\title{
ANALISIS KERENTANAN BENDUNGAN PONRE-PONRE KABUPATEN BONE BERDASARKAN PENGUKURAN MIKROTREMOR DENGAN METODE HVSR
}

\author{
${ }^{1)}$ Wahyudin, ${ }^{2)}$ Sulistiawaty dan ${ }^{3)}$ Nasrul Ihsan \\ Universitas Negeri Makassar \\ 1)e-mail : wahyudinn10@gmail.com
}

\begin{abstract}
Abstrak. Telah dilakukan penelitian tentang analisis kerentanan Bendungan Ponre-ponre Kabupaten Bone berdasarkan pengukuran mikrotremor dengan metode HVSR Tujuan penelitian ini adalah memperoleh nilai kerentanan terhadap gelombang seismik Bendungan Ponre-Ponre . Objek penelitian adalah Bendungan Ponre-ponre Pengambilan data dilakukan dengan menggunakan seperangkat Portable Seismograph TDL 303 S untuk merekam getaran. Pengukuran dilakukan pada 10 titik yang terdiri dari 5 titik di badan bendungan dan 5 titik pada sekitarnya. Data mikrotremor pada gedung diolah menggunakan software Geopsy dengan metode HVSR (Horizontal to Vertical Spectral Ratio). Hasil yang diperoleh, nilai frekuensi dominan adalah $0,43-8,88 \mathrm{~Hz}$, sedangkan untuk nilai periode dominan adalah 0,11-2,32 yang menunjukkan bahwa batuannya merupakan batuan alluvial. Adapun nilai amplifikasi adalah 1,81-4,47. Kerentanan berdasarkan nilai indeks kerentanan berada pada rentang $0,45-9,54$. Sedangkan kerentanan berdasarkan nilai PGA memliki rentang nilai 18,35 - 83,37 dengan penjelasan tidak menimbulkan kerusakan jika terjadi gempa bumi. Berdasrakan hasil tersebut maka, Kerentanan Bendungan Ponre-Ponre berdasarkan nilai frekuensi dominan, amplifiasi, indeks kerentanan, periode dominan, serta PGA secara umum berada pada zona yang masih relatif aman.
\end{abstract}

Kata kunci : amplifikasi, frekuensi dominan, HVSR, kerentanan, PGA.

\begin{abstract}
This research is about analysis seismic vulnerability of Ponre-ponre Dam District of Bone based on microtremor measurement using hvsr method. The purpose of this study was to obtain the value of susceptibility to the seismic waves of Ponre-Ponre Dam. The object of the research is Ponreponre Dam data collection is done by using a set of Portable Seismograph TDL $303 \mathrm{~S}$ for recording vibrations. Measurements are made at 10 points consisting of 5 points in the dam body and 5 points around it. Microtremor data in the building were processed using Geopsy software using the HVSR method (Horizontal to Vertical Spectral Ratio). The results obtained, the dominant frequency value is $0.43-8.88 \mathrm{~Hz}$, while the value of the dominant period is $0.11-2.32$ which indicates that the rock is alluvial rock. The amplification value is 1.81-4.47. Vulnerability based on the value of the vulnerability index is in the range $0.45-9.54$. While vulnerability based on PGA values has a range of values $18,35-83,37$ with the explanation that it does not cause damage if an earthquake occurs. Based on these results, the vulnerability of the Ponre-ponre Dam based on the value of the dominant frequency, amplification, vulnerability index, dominant period, and PGA is generally in a relatively safe zone.
\end{abstract}

Keywords : amplification, dominant frequency, HVSR, vulnerability, PGA

\section{PENDAHULUAN}

Bendungan adalah konstruksi yang dibangun untuk menahan laju air menjadi waduk, danau, atau tempat rekreasi. Seringkali bendungan juga digunakan untuk mengalirkan air ke sebuah Pembangkit Listrik Tenaga Air. Kebanyakan bendungan juga memiliki bagian yang disebut pintu air untuk membuang air yang tidak diinginkan secara bertahap atau berkelanjutan.
Tetapi banyak bendungan di Indonesia mengalami kerusakan, hingga kerusakannya mengakibatkan jebolnya bendungan. Salah satu penyebab dari rusaknya bendungan adalah gejala geologi. Gejala geologi mempengaruhi yang dinding bendungan salah satunya gempa bumi. Salah satu dampak dari gempa bumi adalah kerusakan sturuktur dinding bendungan. Kerusakan pada dinding bendungan disebabkan oleh kekuatan dan kualitas bangunan, kondisi gelogi dan geotektonik suatu daerah terhadap akibat gempa bumi. Kerentanan suatu bendungan 
perlu diketahui untuk mengetahui dampak gempa terhadap bendungan. Salah satu metode untuk mengetahuinya adalah metode mikroseismik.

Metode mikroseismik pada dasarnya adalah merekam getaran alami yang mencerminkan kondisi geologi sutu daerah. Metode pengolahan data pengukuran mikroseismik idealnya terbagi dua, yaitu untuk bangunan bertingkat dan wilayah terbuka. Metode yang ideal untuk bangunan bertingkat adalah metode FSR (Floor Spectra Ratio) sedangkan yang lain adalah HVSR (Horizontal to Vertical Spectral Ratio) Daerah bendungan bukan bangunan bertingkat maka metode yang cocok adalah metode HVSR. Nakamura (1989) memaparkan bahwa metode HVSR membandingkan antara komponen sinyal vertikal dengan komponen sinyal horizontal yang diperoleh dari pengukuran sinyal mikrotremor. Parameter yang dihasilkan pada metode HVSR berupa frekuensi predominan dan faktor amplifikasi. Data frekuensi predominan dan faktor amplifikasi dimanfaatkan untuk menentukan besarnya nilai indeks kerentanan seismik.

Penelitian sebelumnya Wibowo (2014) menggunakan pengukuran data microtremor yang diperoleh dari alat Time Digital Seismograph (TDS) dengan metode Horizontal to Vertical Ratio (HVSR). Kesimpulan yang diperoleh Plotting terhadap titik ukur menghasilkan zonasi klasifikasi potensi kerusakan berdasarkan model PGA. Zonasi spasial pada Bendungan Sermo termasuk ke dalam kategori potensi kerusakan ringan $(0,04 \leq \mathrm{a}<0,15 \mathrm{~g})$ sampai sedang $(0,15 \leq \mathrm{a}$ $<0,34 \mathrm{~g})$ dengan a adalah PGA dan g adalah satuan (gal).

Kerentanan bendungan telah diteliti oleh Pancawati (2017) menunjukkan hasil pengolahan data rekaman mikroseismik. Rekaman sesimik itu antara lain frekuensi dominan tanah (Fo), nilai ketebalan lapisan lapuk (H), nilai indeks kerentanan seismic $(\mathrm{Kg})$, dan nilai Ground Shear
Strain (GSS). Perhitungan nilai dicari menggunakan metode HVSR dan selanjutnya diolah dengan software Geopsy.

Penelitian yang lain oleh Mudamakin (2015) yang bertujuan pemantauan karakteristik respon seismik tanah dan struktur Bendungan Karangkates sebagai langkah awal pemeliharaan. Hasil diperoleh adalah grafik perbandingan komponen vertikal dengan horizontal dan parameter frekuensi dominan.

Analisis mikrotreomr dengan menggunakan metode HVSR juga dilakuakn oleh Sulistiawaty (2017) yang mendapatkan kesimpulan bahwa berdasarkan nilai frekuensi 0,416-0,509 Hz maka lokasi penelitian dominan batuan alluvial, dimana pada titk MG02 merupakan daerah yang paling rentan dengan nilai 105,9918 . Sedangkan berdasarkan nilai PGA yaitu 8,4-9,4 Gal, maka lokasi penelitian termasuk sangat kecil tingkat resiko gempanya.

Dari uraian di atas akan dilakukan penelitian di salah satu bendungan yang terletask Sulawesi. Saat ini, pada pulau Sulawesi terdapat 9 unsur tektonik dan struktur yang dapat memicu terjadinya gempa adalah daerah perpotongan atau persinggungan patahan/subduksi lempeng seperti patahan Walanae, patahan Palu-Koro, patahan Matano-Lawanoppo, patahan Kolaka, patahan Paternosfer, patahan Gorontalo, patahan naik Batui-Balantak, subduksi lempeng laut Sulawesi dan subduksi lempeng Maluku (Kaharuddin, 2011).

Banyaknya lempeng aktif di Sulawesi maka perlu dilakukan penelitian tersebut, terkhusus untuk daerah Sulawesi Selatan. Salah satu bendungan berada di Bone adalah bendungan Ponre-Ponre. Bendungan Ponre-ponre merupakan bendungan dan irigasi terbesar ke-2 di Indonesia yang terletak di Sungai Tinco, anak Sungai Walanae Kecamatan Libureng, Kabupaten Bone memiliki tinggi $55 \mathrm{~m}$ dengan kapasitas tampung bersih (efektif) 60.776648624 juta meter kubik dan mampu mengairi 4.411 hektare sawah 
(psdasulsel.org,). Dari uraian di atas maka dilakukan penelitian tentang "Analisis Kerentanan Bendungan Ponre-Ponre Kabupaten Bone Berdasarkan Pengukuran Mikrotremor dengan Metode Horizontal to Vertical Spektrum Ratio (HVSR)" .

Berdasarkan latar belakang yang telah dikemukakan, maka rumusan masalah dalam penelitian ini adalah bagaimana kerentanan Bendungan Ponre-Ponre berdasarkan pengukuran data mikrotremor dengan metode HVSR ? Sesuai dengan rumusan masalah diatas, maka tujuan yang ingin dicapai dari penelitian ini ialah memperoleh kondisi kerentanan Bendungan Ponre-Ponre berdasarkan pengukuran data mikrotremor dengan metode HVSR.

\section{METODE}

Penelitian ini berlangsung sejak bulan Juni sampai bulan Desember 2018. Pengambilan data penelitian bertempat di Bendungan Ponre-ponre Kecamatan Libureng Kabupaten Bone Provinsi Sulawesi Selatan.

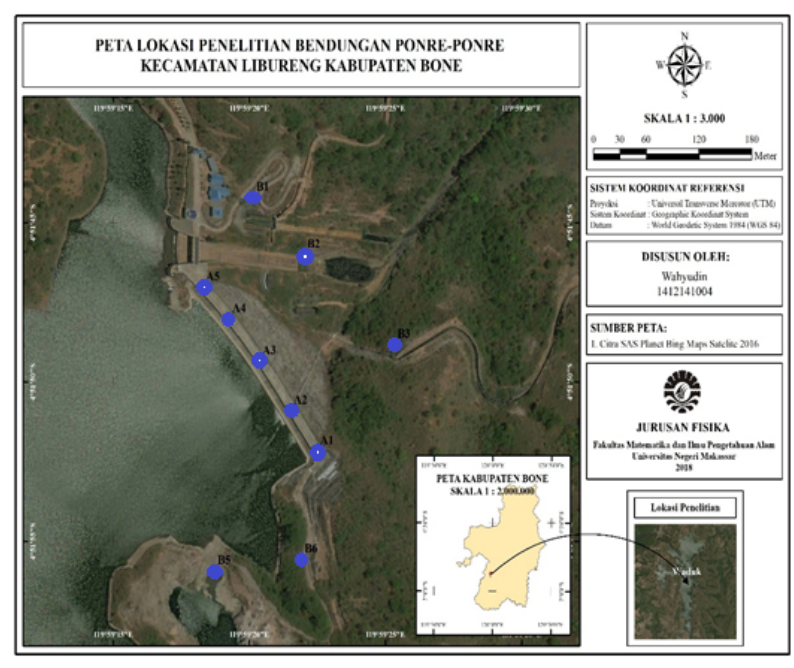

\section{Gambar 1. Lokasi Penelitian}

Pengukuran dilakukan pada 10 titik yang terdiri dari 5 titik di badan bendungan dan 5 titik di sekitar bendungan. Prosedur yang dilakukan dalam penelitian ini adalah :

\section{Persiapan Alat}

Proses persiapan alat mikrotremor meliputi penyiapan peralatan seperti satu buah Digital Portable Seismometer tipe TDL-303 S, Digitizer, Kabel, GPS (Global Position System), GPS Antenna, dan Laptop.

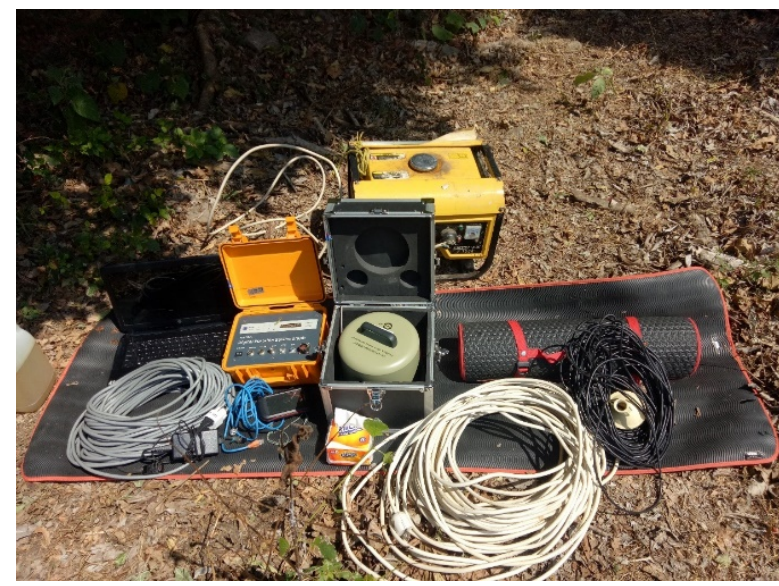

Gambar 2. Portable Seismograph TDL 303 S

\section{Pengambilan Data}

a. Menghubungkan masing-masing kabel konektor dengan seismometer, GPS Antenna, digitizer, dan laptop sesuai dengan fungsinya masing-masing.

b. Meletakkan seismometer di atas permukaan yang keras dan datar

c. Mengatur posisi seismometer agar menghadap ke barat geografis, dengan memakai GPS sebagai acuannya.

d. Melakukan leveling yaitu mengatur kaki-kaki seismometer dengan memutar ke kiri ataupun ke kanan menyesuaikan dengan posisi gelembung air supaya tepat ditengah-tengah yang menandakan posisi alat sudah rata dengan tanah atau lantai.

e. Meletakkan GPS Antenna di tempat yang terbuka dan tidak terhalang dengan apapun agar langsung terhubung dengan satelit.

f. Menyalakan Digitizer dengan menekan tombol ON

g. Pengambilan data menggunakan software mono ST berlangsung selama 40 menit untuk setiap titik pengukuran. Format data hasil pengukuran dari mono ST kemudian 
dikonversi menggunakan DataPro. File diubah terlebih dahulu ke dalam format trace $(* \operatorname{trc})$. Selanjutnya data dalam format trace diubah dalam format miniseed (MSD).

\section{Pengolahan dan Analisis Data}

Analisis data mikrotremor metode HVSR dilakukan dengan menggunakan bantuan software DataPro, software Geopsy, Microsoft Excel. Data yang diperoleh dibuka menggunakan software DataPro yang merupakan program dari alat seismometer TDS. Hasil pengukuran tercatat dalam tiga jenis gelombang yaitu gelombang seismik horizontal (East - West), horizontal (North - South) dan vertikal. Selanjutnya file dalam forrmat miniseed dapat diolah menggunakan software Geopsy.

Tahap awal pengolahan data menggunakan Geopsy adalah menyaring sinyal yang memiliki noise yang besar. Memilih metode HVSR untuk menganalisis data, sehingga memperoleh data amplifikasi dan frekuensi dominan. Data amplifikasi dan frekuensi dominan tiap titik yang diperoleh kemudian digunakan untuk mencari indeks kerentana, periode dominan, serta percepatan pergerakan tanah. Berikut persamaan yang digunakan untuk mencari periode dominan, indeks kerentanan, serta percepatan pergerakan tanah:

$K_{g}=\frac{\left(A_{0}\right)^{2}}{f o}$

$\mathrm{T}_{\mathrm{o}}=1 / \mathrm{f}_{\mathrm{o}} \ldots \ldots \ldots \ldots(2)$

$a=\frac{5}{\sqrt{T_{0}}} 10^{0,61 M-\left(1,66+\frac{3,6}{R}\right) \log R+0,167-\frac{1,83}{R}}$

$K_{g}=$ Indeks kerentanan

$A_{0}=$ nilai amplifikasi

$f_{0}=$ frekuensi dominan $(\mathrm{Hz})$

$T_{0}=$ periode dominan $(\mathrm{s})$

$a=$ percepatan tanah (gal)

$\mathrm{M}=$ magnitude gempa bumi (SR)

$\mathrm{R}=$ hiposenter $(\mathrm{km})$
Percepatan pergerakan tanah memerlukan data gempa bumi yang pernah terjadi di daerah tersebut, oleh karena itu digunakan data gempa yang terjadi pada 8 April 1993 di Ulaweng dengan magnitude gempa 5,5 SR dengan kedalaman $35 \mathrm{~km}$. Pemilihan data gempa tersebut karena gempa tersebut dekat dengan lokasi penelitian.

\section{HASIL DAN PEMBAHASAN}

Data pengukuran mikrotremor lokasi ditunjukkan pada lokasi pengambilan data. Data pengukuran diolah menggunakan metode HVSR untuk memperoleh nilai frekuensi dominan dan amplifikasi. Selanjutnya data tersebut digunakan untuk mencari nilai periode dominan, indeks kerentanan serta percepatan tanah. Seperti yang ditunjukkan pada tabel berikut.

Tabel 1. Tabel Pengolahan Data

\begin{tabular}{cccccccc}
\hline Titik & Lintang & Bujur & F & A & Kg & T & PGA \\
\hline A1 & 4.8645 & 119.989 & 8.88 & 3.74 & 1.57 & 0.11 & 83.37 \\
A2 & 4.8641 & 119.989 & 3.63 & 4.28 & 5.04 & 0.28 & 53.28 \\
A3 & 4.8513 & 119.989 & 3.66 & 4.47 & 5.45 & 0.27 & 53.52 \\
A4 & 4.8635 & 119.988 & 5.11 & 3.51 & 2.42 & 0.20 & 63.23 \\
A5 & 4.8630 & 119.988 & 3.11 & 2.51 & 2.02 & 0.32 & 49.37 \\
B1 & 4.8621 & 119.989 & 0.43 & 2.03 & 9.54 & 2.32 & 18.35 \\
B2 & 4.8628 & 119.989 & 1,49 & 2.30 & 3,55 & 0.67 & 34.14 \\
B3 & 4.8635 & 119.990 & 4.38 & 1.40 & 0.45 & 0.23 & 58.52 \\
B4 & 4.8653 & 119.989 & 1.71 & 1.81 & 1.91 & 0.58 & 36.57 \\
B5 & 4.8825 & 119.822 & 2.02 & 3.27 & 5.31 & 0.50 & 39.71 \\
\hline & Pengukuran & mikrotremor menghasilkan
\end{tabular}
dua hasil parameter yaitu frekuensi dominan dan ampilfikasi. Nilai frekuensi berkisar $0,43-8,88$ $\mathrm{Hz}$, dimana badan bendungan cenderung lebih besar nilainya dibanding dengan area sekitar bendungan. Nilai frekuensi pada badan bendungan berkisar 3,11- 8,88 Hz dimana titik terendah pada titik A5 dan tertinggi pada tiitk A1. Terlihat bahwa titik A1 memiiki nilai yang paling tinggi dengan perbedaaan yang sangat signifikan dari titik yang lain. Hal ini diduga karena pada saat pengambilan data, kondisi angin saat itu lumayan kencang sehingga mempengaruhi sensitivitas seismometer. Jika nilai tersebut diklasifikasikan dengan klasifikasi tanah berdasarkan nilai 
frekuensi oleh Kanai, maka titik A1 dan A4 memiliki kedalaman sedimen $5 \mathrm{~m}$. Sedangkan untuk titik A2,A3 dan A5 yang berada pada rentang 2,5 - $4 \mathrm{~Hz}$ memiliki ketebalan sedimen 510 meter. Hal ini menunjukkan bahwa kedalaman penyusun badan bendungan berkisar $5-10 \mathrm{~m}$. Menurut Koesuma (2017) ketebalan sedimen akan mempengaruhi respon bangunan yang ada di atas permukaan apabila terjadi gempa bumi karena magnitudo gempa akan teramplifikasi. Karena kedalaman sedimen pada bendungan hanya 5-10 meter maka gempa bumi hanya sedikit mengalami amplifikasi yang artinya masih aman.

Adapun untuk nilai sekitar bendungan berkisar dari 0,43 - 4,38 Hz. Dengan identifikasi bahwa area tersebut terdiri atas batuan alluvial dengan yang terbentuk dari sedimentasi delta, top soil, dan lumpur. Hal ini sesuai degan kondisi daerah sekitar bendungan yeng merupakan daeran aliran sungai. Menurut Saputra (2010), kerentanan gempa di daerah aliran sungai berada pada rentang rendah hingga menengah, jadi dapat dikatakan bahwa daerah sekitar bendungan masih dalam keadaan aman.

Adapun sebaran nilai amplifikasi di badan bendungan berkisar 2,51-4,47 dengan titik A5 sebagai nilai terendah dan A2 sebagai nilai tertinggi. Secara umum berdasarkan klasifikasi nilai faktor amplifikasi oleh (Sitorus, 2017) klasifikasi zona amplfikasi di badan badan bendungan masuk dalam kategori sedang karena nilai ampifikasi pada titik A1-A4 berada pada rentang 3-6. Adapun daerah sekitar bendungan berada pada rentang 2,03 - 3,27 dengan B1 sebagai nilai terendah dan B5 sebagai nilai tertinggi. Secara keseluruhan klasifikasi amplifikasi di daerah sekitar bendungan berada pada kategori rendah, karena nilai B1-B4 berada $<3$. Arti dari klasifikasi mengindikasikan bahwa jika terjadi gempa bumi maka gelombang akan dikuatkan dari rendah hingga sedang, sehingga masih relatif aman.

Selanjutnya nilai indeks kerentanan ditunjukkan oleh hasil pengolahan data menunjukkan bahwa nilai indeks kerentanan di badan bendungan berkisar 1,57 - 5,45. Dimana titik A1,A4 dan A5 berada zona klasifikasi rendah karena berada di rentang $<3$, sedangkan titik A2 dan A5 berada pada rentang 3-6 sehingga masuk di zona klsifikasi sedang. Hal ini menjadikan kerentanan di badan bendungan masih dalam keadaan aman.

Adapun di daerah sekitar bendungan berada pada rentang 0,45 - 9,54 dengan nilai teringgi pada titik B1 dan terendah di titik B3. Daerah sekitar terbagi atas tiga zona. Titik B1 berada pada zona tinggi karena nilai $>6$, untuk titik B2 dan B5 berada pada zona sedang karena di rentang $3-6$, sedangkan titik B3 dan B4 berada pada zona rendah dengan nilai $<3$. Terlihat bahwa titik B1 memiliki nilai tinggi dengan perbedaan yang signifikan dengan titik yang lain, hal ini terjadi karena titik pengambilan data berbeda jenis dengan titik yang lain. Dimana titik B2-B5 dilakukan pada tanah, sedangkan titik B1 dilakukan pada batuan keras yang terbuat dari semen.

Hasil yang lain adalah nilai periode dominan dimana periode dominan adalah kebalikan dari frekuensi dominan, yang juga mengindikasikan karakter lapisan batuan yang ada di suatu wilayah. Nilai pada badan bendungan bernilai $0,11-0,32$ s. Untuk nilai di sekitar bendungan berada pada rentang $0,23-2,32 \mathrm{~s}$. Karena nilai periode dominan adalah kebalikan dari frekuensi dominan, meskipun nilainya berkebalikan, tetapi klasifikasi pada titiknya akan sama. Jadi kedalaman sedimen pada bendungan hanya 5-10 meter maka gempa bumi hanya sedikit mengalami amplifikasi yang artinya masih aman. Sedangkan unutk sekitar bendungan merupakan batuan alluvial yang tersusun atas sedimen lumpur, top soil, dll.

Dengan nilai periode dominan setiap titik dan data gempa yang telah ditentukan sebelumya, maka secara keseluruhan nilai percepatan getaran tanah adalah 18,35 - 83,37 gal. Nilai terendah adalah 18,35 gal yang berada pada titik B1 sedangkan nilai tertinggi berada pada titik A1 dengan nilai 83,37 . Nilai yang mempengaruhinya adalah nilai periode dominan, semakin kecil nilai periode dominan maka semakin tinggi nilai PGA, begitupun sebaliknya. Berdasarkan klasifikasi oleh (www.bmkg.com) maka jika terjadi gempa di daerah tersebut dengan parameter gempa yang telah ditentukan sebelumya kondisi daerah berada 
pada warna hijau dengan deskripsi sederhana dirasakan, dimana akan dirasakan oleh orang banyak tetapi tidak menimbulkan kerusakan. Benda-benda ringan yang digantung bergoyang dan jendela bergetar dengan skala MMI III-V. Berdasarkan deskripsi tersbut, maka kerentanan di Bendungan Ponre-ponre berdasarkan nilai PGA masih aman.

\section{KESIMPULAN}

Berdasarkan hasil penelitian dan pembahasan dapat disimpulkan Kerentanan Bendungan Ponre-Ponre berdasarkan nilai frekuensi dominan, amplifiasi, indeks kerentanan, periode dominan, serta PGA secara umum berada pada zona yang masih relatif aman.

\section{DAFTAR RUJUKAN}

Arifin, S.S, dkk. 2013. Penentuan Zona Rawan Guncangan Bencana Gempabumi Berdasarkan Analisis Nilai Amplifikasi HVSR Mikrotremor Dan Analisis Periode Dominan Daerah Liwa dan Sekitarnya. Jurnal Geofisika Eksplorasi Vol. 2/No. 1.

Badan Perencanaan Pembangunan Nasional. 2013. Rancangan Rencana (Draf Rencana) RT/RW Kabupaten Bone.

BMKG. Skala Intensitas Gempabumi (SIG) $B M K G$. Diakses pada web https://www.bmkg.go.id/gempabumi/skal a-intensitas-gempabumi.bmkg tanggal 11 Januari 2019 Jam 20.00.

Febriani, Y., Daruwati, I., Hatika, R. 2013. Analisis Nilai Peak Ground Acceleration dan Indeks Kerentanan Seismik Berdasarkan Data Mikroseismik Pada Daerah Rawan Gempabumi di Kota Bengkulu. Jurnal Ilmiah Edu Research Vol.2 No.2 Desember 2013

Haris, A., Irjan. 2013. Analisis Percepatan Getaran Tanah Maksimum Wilayah Yogyakarta dengan Metode Atenuasi Patwardhan. Jurnal Neutrino Vol.5, No. 2 April 2013.
Kaharuddin dkk. 2011. Perkembangan Tektonik dan Implikasinya terhadap Potensi Gempa dan Tsunami di Kawasan Pulau Sulawesi. Proceedings J CM Makassar 2011 The $36^{\text {th }}$ HAGI and $40^{\text {th }}$ IAGI Annual Convention and Exhibition Makassar, 26-29 September 2011

Kanai, K. 1983. Engineering Seismology. University of Tokyo Press. Tokyo.

Koesuma, S., Pratiwi, S., Legowo, B. 2017. Penentuan Ketebalan Sedimen Menggunakan Metode Mikrotremor di Kota Surakarta . Risalah Fisika Vol. 2 no. 1 (2018) 25-28

Kramer, S.L. 1996. Geotechnical Earthquake Engineering. Prentice Hall. Upper Saddle River, New Jersey.

Lachet, C. \& P.Y. Brad.1994. Numerical and Theoretical Investigations on The Possibilities and Limitations of Nakamura's Technique. Journal Physic Earth, 42: 377-397.

Lay dan Wallace. 1995. Modern Global Seismology. USA : Academic Press

Marjiyono, Soehaimi, \& Kamawan. 2007. Identifikasi Sesar Aktif Daerah Cekungan Bandung Berdasarkan Citra dan Kegempaan. Jurnal Sumber daya Geologi, 18(2): 81-88.

Mudamakin, P.B., Rudiyanto, A., Rohadi, S., Amalia, R., 2015. Studi Awal Respon Dinamis Berdasarkan Pengukuran Mikrotremor Di Bendungan Karangkates Malang, In: Prosiding Seminar Nasional Fisika (E-Journal). p. SNF2015-IX.

Muhtar dkk. 2014. Indeks Kerentanan dan Amplifikasi Tanah akibat gempa dii wilayah Universitas Muhammadiyah Jember. Media Teknik Sipil Agustus 2014, Hal. 158 - 162

Nakamura, Y., 2000, Clear Indentification of Fundamental Idea of Nakamura's Technique and Its Application, Tokyo University, Japan. 
Nakamura, Y., 2008, On the $H / V$ Spectrum, The 14th World Conference on Earthquake Engineering, Beijing.

Nakamura, Y. 1989. A Method for Dynamic Characteristic Estimation of Subsurface using Microtremor on The Ground Surface. Q.R. of RTRI. Vol. 30, No. 1, page 25-33.

Pancawati, K.D., Supriyadi, S., Khumaedi, K. 2017. Identifikasi Kerentanan Dinding Bendungan dengan Menggunakan Metode Mikroseismik (Studi Kasus Bendungan Jatibarang, Semarang). Unnes Phys. J. 5, 21-26.

PSDASULSEL. Bone Miliki Bendungan Terbesar Kedua d Indonesia. Diakses pada http://psdasulsel.org/index.php/arsipberita/sda-sulsel/118-bone-milikibendungan-terbesar-kedua-di-indonesia. Tanggal 10 Juni 2018 jam 21.00.

Refrizon dkk. 2013. Analisis Percepatan Getaran Tanah Maksimum dan Tingkat Kerentanan Seismik Daerah Ratu Agung Kota Bengkulu. Proseding Semirata FMIPA Universitas Lampung.

Saputra, S.E.A., Suhaimi, A., Mulyasari, F. 2010. Makrozonasi dan Mikrozonasi Kerentanan Bencana Gempa Bumi di Wilayah Ende sebagai Data dasar Perencanaan dan Pengembangan Wilayah. Jurnal Geologi Indonesia, Vol. 5 No. 3 September 2010: 171-186

Sitorus, N.M.H., Purwanto, M.S., Utama, W. 2017. Estimasi Ketebalan Lapisan Sedimen dan Amplifikasi Desa Olak Alen Blitar Menggunakan Metode Mikrotremor HVSR. JURNAL TEKNIK ITS Vol. 6, No. 2, 2337-3520.

Sulistiawaty, dkk. 2017. Analisis Mikrozonasi Seismik pada Kecamatan Galesong Kabupaten Takalar Sulawesi Selatan. Jurnal Sainsmat, Maret 2017, Halaman 28-38 Vol. VI, No. 1

Telford, M.W., L.P. Geldart, R.E. Sheriff. 1976. Applied Geophysic. Cambridge University Press.
Wibowo, N.B dan Gunawan, A. 2014. Analisis Spasial Respon Bendungan terhadap Model Peak Ground Acceleration (PGA) Berdasarkan Karakteristik Mikrotremor, Geologi Regional dan Amatan Instrumentasi pada Bendungan Sermo Kulonprogo. Indonesian Journal of Applied Physics (2014) Vol.4 No.1 Halaman 115. 